\title{
Varicocele in Children and Adolescents: A Challenge for Diagnosis and Treatment Indications
}

\author{
Guy Bogaert* , Marleen van den Heijkant, Maarten Albersen \\ Department of Urology and Pediatric Urology, UZLeuven, KU Leuven, Leuven, Belgium
}

\section{Article info}

Keywords:

Varicocele

Subfertility

Pubertal adolescent

\begin{abstract}
Varicocele, fertility, and paternity are terms that are frequently used in a common topic of clinical and pathologic conditions; however, any form of direct relationship has not been found. Is the high incidence and presence of a varicocele in boys, adolescents, and adults a normal variant? The hypotheses for a possible association between varicocele and fertility are based on issues such as temperature, volume, and growth of the testis, and sperm count, and indirect evidence indicating improved semen parameters after varicocele repair. However, what it comes down to, is the chance to father a child-to introduce pregnancy rather than a sperm count difference. This article highlights evidence-based findings and recent observations for a better understanding of which boys and adolescents would benefit from treatment or reassurance.

(C) 2017 European Association of Urology. Published by Elsevier B.V. All rights reserved.

\footnotetext{
* Corresponding author. UZLeuven Urologie, Herestraat 49 UZLeuven Urologie, Vlaams-Brabant, Leuven 3000, Belgium. Tel.: +3216346930.

E-mail address: guy.bogaert@uzleuven.be (G. Bogaert).
}

\section{Etiology and epidemiology of varicocele}

The approximate incidence of varicocele in young adolescents and adults is around 16\%; however, this incidence may be underestimated, as they might not be detected during "regular clinical exams" [1]. The sudden higher incidence during puberty, compared with childhood, is most probably due to puberty-associated testicular growth and increased blood flow [2].

Anatomical differences between left and right venous drainage of the testis at the level of the testicular vein are used to explain the presence of dilated veins of the plexus pampiniformis, mainly on the left side. On the right side, the testicular vein drains into the vena cava in a sharp angle. On the left side, however, the testicular vein drains into the left renal vein in an almost $90^{\circ}$ angle. The nutcracker effect is thought to occur when the left renal vein is compressed between the superior mesenteric artery and aorta, proximal of the point where the left testicular vein runs in it, which is thought to increase the hydrostatic pressure resulting in varicocele formation [3].

\section{Prevalence of varicocele in men from couples with fertility problems}

The prevalence of varicocele is $20-40 \%$ in men who request investigation of fertility problems [4]. Another observation is the fact that patients with a varicocele have a higher incidence of an ipsilateral smaller testis and poorer sperm quality compared with patients without a varicocele [5]. In conclusion, there is a definite association between the presence of a varicocele and male fertility; however, the cause and relationship between the varicocele and fertility is unknown [6].

Depending on how one looks at numbers and incidence, only $15-20 \%$ of men with a varicocele require treatment for 
infertility, suggesting that most men with a varicocele have no fertility problems [7].

Controversial data exist on the effect of varicocele grade on semen quality. Recently, Al-Ali et al [8] showed that oligozoospermia was present twice as much in patients with a grade III varicocele compared with patients with a grade I or II varicocele. They also stated that sperm density significantly decreased with increasing grade of varicocele. These results correlate with the previously published results of Steckel et al [9] who stated that men with a grade 3 varicocele had lower sperm counts and poorer fertility indexes compared with men with grades 1 and 2 varicocele. Krishna Reddy et al showed total sperm motility of 30\%, 29\%, and 21\% (World Health Organization lower reference limit [range]: 40 [38-42]) and mean sperm concentrations of 16.8 million/ml, 14.7 million/ml, and 9.75 million/ml (World Health Organization lower reference limit [range]: 15 [1216]) in men presenting with infertility with grade 1,2 , and 3 varicocoele, respectively [10].

However, Shiraishi et al [11] and Diamond et al [12] reported no significant difference between varicocele grade and semen quality.

It has also been realized that azoospermia and severe oligoasthenospermia are extremely rare in pure varicocele patients [3]. In contrast, it is even estimated that almost $15 \%$ of men with azoospermia carry microdeletions of the long arm of chromosome Y [13]. Patients with azoospermia or severe oligoasthenospermia and a varicocele will probably not benefit from surgical treatment of the varicocele. Those patients would rather benefit from genetic counseling.

\section{The importance of testis growth and volume}

Testicular growth impairments associated with the presence of a varicocele have been variably reported; some studies have found growth arrest while others have not [14-16].

The volume of the testis is strongly related to fertility and sperm count. Although the American Society for Reproductive Medicine Practice Committee recommends obtaining a semen analysis in pediatric patients presenting with a varicocele, even in the absence of significant testicular atrophy. Semen parameters do not belong in routine assessment of a varicocele in an adolescent. In addition, there are significant barriers to performing semen analysis in an adolescent, more specifically from the view of the adolescent himself, the parents, and the practitioner [17]. There is also a lack of representative normal semen values in the adolescent age group and in addition, this may be influenced by the difference in Tanner stage and development.

It is known from previous studies that a $10 \%$ size variance between testes without associated abnormalities such as presence of a varicocele is considered as normal [18].

Diamond et al [12] showed that ultrasonographically derived volume differentials greater than $10 \%$ between normal and affected testes in Tanner $\mathrm{V}$ adolescents correlate with a significantly decreased sperm concentration and total motile sperm count.
Sigman and Jarow [19] showed a statistically higher incidence of hypotrophy in grade 3 varicoceles (73\%) compared with grade 1 and 2 varicoceles (49\% and 55\%, respectively). These authors also found a significant difference in total motile sperm count between men with or without testicular hypotrophy; however, there seemed to be a trend of decreasing sperm count with increasing difference in testicular size, although this was not statistically significant.

Haans et al [20] and Laven et al [21] found in their studies that left testicular growth failure in patients with varicocele relative to controls correlated with lower total sperm number but they did not find a correlation with sperm concentration. In contrast, Guarino et al [22] found no predictive value of testicular volume measurement with regard to semen analysis in Tanner $\mathrm{V}$ adolescents and no statistical difference in testicular volume difference in patients with versus without varicocele.

Skoog et al [7] have pointed out an important issue in the difficult interpretation and the contradictory results of previous studies: the growth of the testis rather than the volume itself. They explained that a volume difference between the two testes becomes clear in adolescents with a varicocele during the rapid growth of the testes during puberty. They also stated that the loss of testicular volume is accompanied by a decrease in sperm count and advocate the early diagnosis of the disease as this is important for the prevention of sperm impairment and infertility.

A recent study that has investigated the relationship between testicular volume differential, total testis volume, and total motile sperm count in adolescents with a varicocele have found that a testicular volume differential of greater than $20 \%$ doubles the odd of a lower total motile sperm count; however, if the total volume of both testis equals $30 \mathrm{ml}$ or more, the total motile sperm count is found to be normal [23].

\section{Paracrine and endocrine regulation of the spermatogenesis}

The testis has an endocrine and exocrine function, where exocrine function is mainly controlled by Sertoli cells, under the influence of follicle stimulating hormones, and they regulate the spermatogenesis by activin, androgen binding protein, and direct interactions with spermatogonia and spermatids [3]. The endocrine function is then mainly controlled by the Leydig cells and they regulate in turn by achieving a high intratesticular testosterone concentration. The Leydig cells also produce the epidermal growth factor and this controls the mitotic division of the germinal epithelium and stimulates the division of peritubular myoid cells, that in return produce another paracrine hormone, peritubular myoid substance. The list of paracrine substances involved in the molecular mechanisms controlling spermatogenesis is steadily increasing due to the continuous efforts of research. The understanding of endocrine, paracrine, and even neurotropins on spermatogenesis, together with the eventual ability to measure these 
substances, may allow us one day to predict which adolescent and/or adult with a varicocele would benefit from a surgical intervention of the varicocele.

\section{The diagnosis of a varicocele}

In the diagnosis of a varicocele, there is first of all the clinical diagnosis and staging of the varicocele. Furthermore, the documentation of the testicular volume by ultrasound is, by some, considered to be of importance. Other investigations, such as venography, thermography, and endocrine evaluation are not recommended for the routine evaluation of an adolescent patient with a varicocele.

The varicocele is clinically graded in a grade I-III following the description of Dubin and Amlar [24]. A varicocele grade I is palpable at Valsalva maneuver only, a varicocele grade II is palpable without the Valsalva maneuver, grade III is visible at distance. The issue of subjectivity in the diagnosis of a varicocele has long been a subject of debate. In a study by Hargreave and Liakatas [25], two researchers independently examined the same cohort of patients and diagnosed varicocele in $19 \%$ and $31 \%$, respectively. Agreement in the diagnosis occurred in only $56 \%$ of cases. The prevalence of the diagnosis of varicocele is therefore due to examiner bias. Men attending infertility clinics undergo a more extensive physical examination and special attention is made to the presence of a varicocele. It becomes obvious that in infertile men, low-grade varicocele will be picked up, whereas in the general population, which usually acts as the control group, it might not be.

The documentation of a varicocele, as well as the documentation of the bilateral testicular volumes using (Doppler) ultrasound is also controversial. Some authors suggest that a testicular volume difference of at least $2 \mathrm{ml}$ should be regarded as abnormal, as a risk for fertility impairment, and suggest a Doppler ultrasound to detect a so-called grade 0 varicocele (clinical not detectable) [26]. Diamond et al [12] considers a testis that is $>2 \mathrm{ml}$ or $<10 \%$ compared with the other testis to be hypoplastic in adolescents. However, a recent large review of the literature has shown that there is limited evidence that adolescent varicocele repair would improve paternity in adulthood, so the value and expense of serial ultrasound evaluation is not to be considered beneficial [27].

A secondary varicocele could occur due to extension of or direct compression of (Wilms) tumor into/onto the renal vein and inferior vena cava. In case of a right-sided varicocele, a renal ultrasound is recommended.

\section{Effects of varicocelectomy}

A varicocelectomy consists of ligation or occlusion of the testicular vein with subsequential venous drainage via the lymphatic vessels. The treatment effect of varicocelectomy on fertility is only known in adults (with fertility problems) and nothing is known on the eventual preventive effect of treatment during puberty or adolescence. In addition, for many years the association between varicocele and fertility was based on studies showing improvement (30-60\%) in semen parameters after varicocelectomy [28,29]. However, these studies showed important methodological disadvantages, in that the main outcome was improvement in semen parameters, and not pregnancy rate, let alone live birth rate, in addition to the fact that there was the lack of a control group.

Nieschlag et al [30] performed a prospective controlled study on the treatment of varicocelectomy with pregnancy rate as the main outcome. In addition to the fact of comparing varicocelectomy counseling only, this study compared two techniques of varicocelectomy, the surgical ligation of the spermatic vein, and angiographic embolization. No statistically significant difference was found in pregnancy rates between the two groups, during a period of $12 \mathrm{mo}$, in spite of improved semen parameters.

The most recent Cochrane review focusing on the surgery or embolization for varicoceles in subfertile men indicates that there is evidence suggesting that treatment of a varicocele in men from couples with otherwise unexplained subfertility may improve a couple's chance of pregnancy. However, findings were determined to be inconclusive as the quality of the available evidence is very low and more research is needed with live birth or pregnancy rate as the primary outcome [31]. Looking at the data in detail, the odds ratio for achieving clinical pregnancy was 1.47 (95\% confidence interval: 1.05-2.05) after varicocele ligation or occlusion in men with decreased semen parameters and varicocele, and the odds ratio rose to 2.39 (95\% confidence interval: 1.56-3.66) when studies concerning subclinical varicocele were omitted. It should be noted, however, that heterogeneity between study results was very high, and evidence quality was very low. When regarding studies of high quality only, no significant effect on clinical pregnancies was found. Based on these observations, the current European Association of Urology guidelines on male infertility state that varicoceles should not be treated in infertile men who have normal semen analysis and in men with a subclinical varicocele (grade $\mathrm{A}$ recommendation), while it is recommended that treatment is advised when a clinical varicocele is detected in men with oligospermia and no other apparent cause of infertility (grade A recommendation) [32].

Concerning varicocele repair in adolescents, Cayan and Woodhouse [33] showed that a preoperative weak and smaller testis could regain firmness and catch up in growth after varicocelectomy but only if performed at $<14 \mathrm{yr}$ of age. The question remains whether the so-called catch-up growth is due to postsurgical edema [34] or is a real increase in testicular tissue [35]. Again, there is no evidence, but in general it is reported that a part of this catch-up growth may be attributed to interstitial edema due to the division of lymphatic vessels [34].

Paduch and Niedzielski [36] reported in a prospective study a group of 88 boys, in whom catch-up growth was observed within $12 \mathrm{mo}$. Li et al [35] conducted a recent meta-analysis on the effect of varicocelectomy on testicular volume in children and adolescents and suggested clear advantages of surgical intervention on reducing testicular 
hypotrophy when the discrepancy is less than $10 \%$; however, prospective and controlled studies are needed.

\section{Varicocele treatment: which technique?}

A varicocele can be treated by (sub)inguinal microsurgical ligation, open, or laparoscopic suprainguinal ligation and percutaneous retrograde or open antegrade embolizing or sclerosing techniques. For surgical high ligation, the use of surgical loups is recommended as the internal spermatic artery is $0.5 \mathrm{~mm}$ in diameter at the level of the internal ring. Moreover, a lymphatic-sparing varicocele is thought to prevent hydrocele formation [37-42]. Angiographic occlusion of the internal spermatic veins is performed by retrograde or antegrade application of a sclerosing agent into the spermatic veins and is considered as a lymphatic as well as internal spermaticartery-sparing repair [43-45], but is associated with radiation burden, which is less controllable in the antegrade technique. Reported recurrence rates are usually $<10 \%$; however, standardized follow up data are lacking. Of many potential approaches, microsurgical repair results in fewer complications and lower recurrence rates compared with the other techniques but requires microsurgical training.

\section{Will screening and treatment in pubertal boys change their ultimate paternity chance later in life?}

To our knowledge, Belgium is the only country worldwide where the diagnosis of a varicocele is included in the medical screening of high school/secondary school boys aged between $12 \mathrm{yr}$ and $18 \mathrm{yr}$. As the screening began in 1987 , a significant number of patients have reached the age wishing to have children. A study was set up in UZ Leuven, where all patients that were seen in the pediatric urology clinic in pubertal age and were now $30 \mathrm{yr}$ of age or older, were contacted and asked if they wished to have children and if they had become a father [46]. Effective paternity was $85 \%(61 / 72)$ in the conservative group and $79 \%(67 / 86)$ in the treatment group ( $p>0.05$; Fig. 1$)$. In a subanalysis of the patients with a smaller left testis preoperatively, a paternity of $82 \%$ (14 of 17 patients) was found in the treated group and $90 \%$ ( 9 of 10 patients) in the conservative group ( $p=1$; Fig. 2). In addition, the incidence of subfertility as a couple was compared and again found no difference between the two groups: 16 of 75 couples (21\%) in the treated group and 6 of 55 couples (11\%) in the untreated group were subfertile $(p=0.16)$. In this subgroup, men with a smaller left testis preoperatively were evaluated and four out of 17 couples (23\%) in the treated group and two out of 10 couples $(20 \%)$ in the conservative group were considered as subfertile $(p=0.6)$. In a different study, in up to $30 \%$ of patients, a number of psychological reactions, such as anxiety or depressed mood, were observed in boys who were told that they had a varicocele [47]. In conclusion, there is no beneficial effect of pubertal screening and treatment for a varicocele regarding chance of paternity later in life.

\section{Indications for treatment during adolescence}

The European Urology pediatric guidelines 2016 recommend the following criteria for varicocele treatment in children and adolescents: varicocele associated with a small testis, an additional testicular condition affecting fertility, bilateral palpable varicocele, pathological sperm quality in older adolescents, or a symptomatic varicocele. The question is whether a worldwide screening and early treatment for all adolescents with a varicocele would improve men's overall fertility will remain unanswered and questioned. The fact that we are unable to identify the specific subgroup of adolescents with a clinical varicocele who would benefit from a varicocele treatment makes screening and early treatment not justifiable.

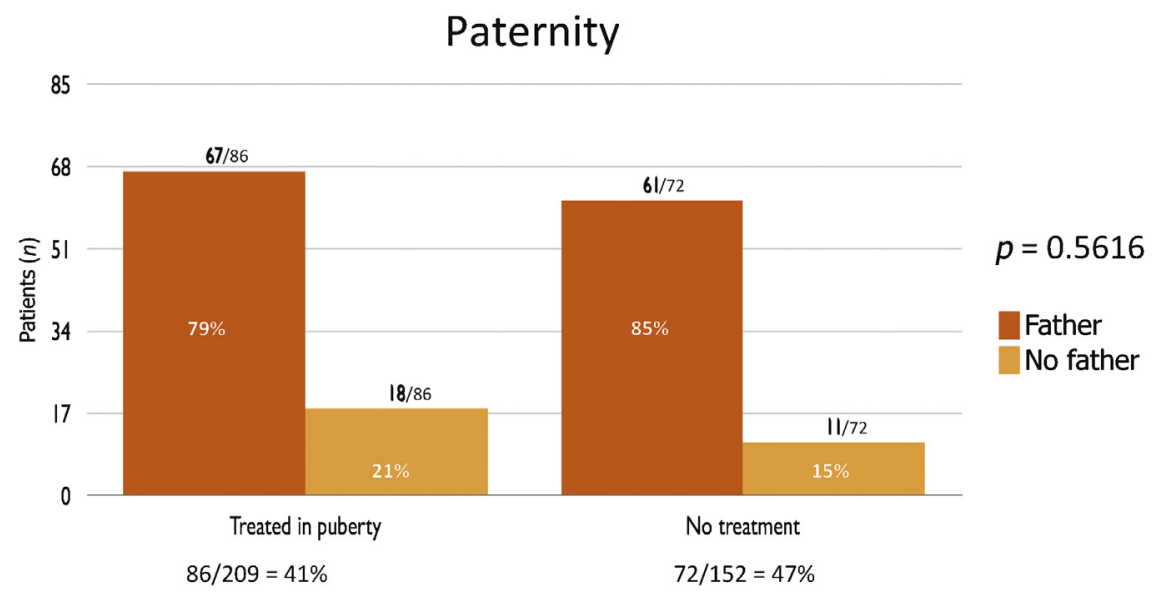

Fig. 1 - Of survey respondents, 27 (8\%) had smaller testis (by more than $2 \mathrm{ml}$ as measured using a Prader orchidometer in pubertal testes $4-12 \mathrm{ml}$ ). Of those patients, $17(63 \%)$ underwent antegrade sclerotherapy during puberty, of whom $14(82 \%)$ achieved paternity. Ten patients (37\%) were followed without further treatment, of whom nine (90\%) became fathers. The incidence of smaller testis was similar in both groups (8\% vs $7 \%$ ).

Note. From “Pubertal Screening and Treatment for Varicocele do not Improve Chance of Paternity as Adult," by G. Bogaert, C. Orye, and G. de Win, 2013, Journal of Urology, 189, p. 2298. Copyright 2013, Elsevier. Adapted with permission. 


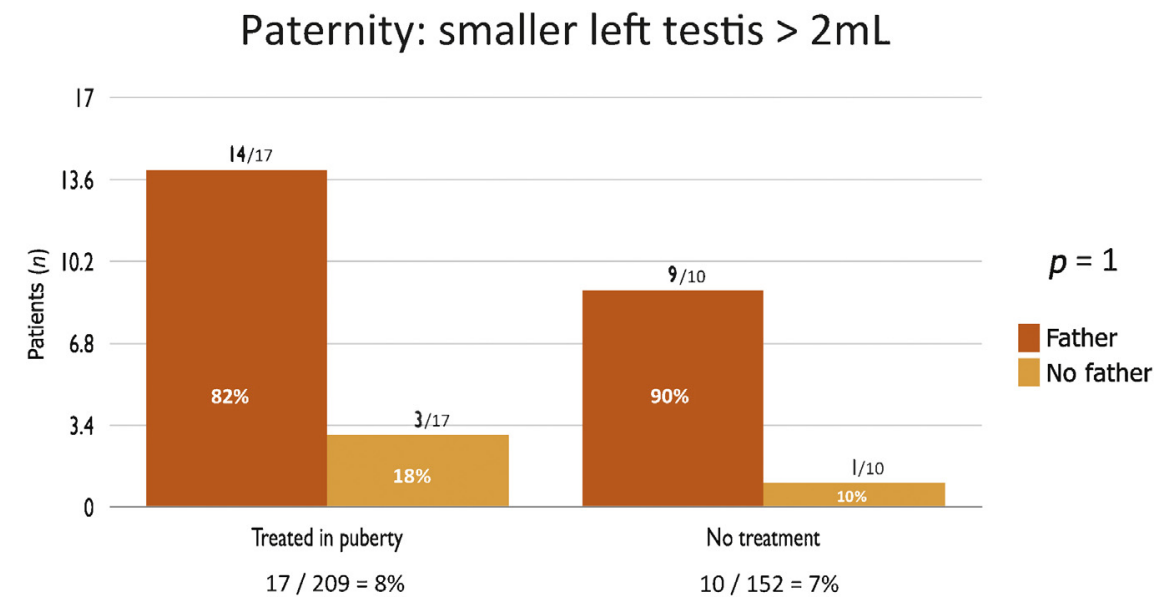

Fig. 2 - Of survey respondents, 158 (44\%) had a desire to have children. Of those patients, 86 (55\%) underwent antegrade sclerotherapy during puberty and $67(78 \%)$ became fathers with proven successful paternity. A total of 72 patients (46\%) were followed without further treatment, of whom 61 (85\%) became fathers. The desire to have children was similar in both groups (41\% vs $47 \%)$.

Note. From "Pubertal Screening and Treatment for Varicocele do not Improve Chance of Paternity as Adult," by G. Bogaert, C. Orye, and G. de Win, 2013, Journal of Urology, 189, p. 2298. Copyright 2013, Elsevier. Adapted with permission.

Table 1 - Indications for treatment of a varicocele during puberty or adolescence

- Absolute medical indications none

- Relative indications

growth difference change of the left testis of $>20 \%$ over a $1-y r$

observation period

volume difference of $>20 \%$ of the left testis and a total testes volume

$<30 \mathrm{ml}$ in a Tanner $4-5$ boy

$>$ grade 3 varicocele (volume of the varicocele $>2 \times$ the size of the left testis)

- Minor indications

abnormal semen analysis

softer left testis

pain or discomfort at the left testis

anxiety (boy or parental)

family history of subfertility and varicocele

asymmetric scrotal appearance

The only relative indication universally agreed upon is a smaller ipsilateral testis and a large left-sided varicocele. A possible indication could be the growth difference over a period of at least $1 \mathrm{yr}$. Other minor indications, such as abnormal semen analysis, a so-called "softer" testis, pain or discomfort, patient or parental anxiety, or asymmetric scrotal appearance, should extensively be discussed with the patient and his parents regarding benefits and risks of surgery (Table 1 ).

From an economical point of view, antegrade sclerotherapy is the first choice of treatment as it is far less expensive than any other alternative [48].

\section{Conclusions}

It is clear that the absolute majority of adolescents with a varicocele will have no fertility problems and a normal paternity chance [46]. In addition, systematic screening and treatment during puberty has no beneficial effect on chance of paternity. This knowledge should be explained during counseling of adolescent boys and their parents at the time of the diagnosis of a varicocele as they may become stressed and anxious due to the uncertainty of the prognosis of this diagnosis.

As many scientists believe that the indication for varicocelectomy should include a very narrow group of adolescent boys and infertile men, there are no clear accepted criteria regarding the selection of these adolescents. If advanced molecular biology techniques to measure significant endocrine or paracrine substances or genetic screening for microdeletions of the long arm of the Y chromosome, would become universally available as screening, it may change the recommendation for screening adolescents.

Between the growing pubertal boy, the adolescent man, and the subfertile patient, there are many other factors than just the presence of a varicocele that may influence the fertility of the man, such as smoking, obesity, diabetes, stress, and environmental factors [49].

Until more valid data are available, it is recommended to yearly follow adolescent boys who have a left-sided varicocele and either a smaller left testis or bilateral small testes for testicular growth.

\section{Conflicts of interest}

The authors have nothing to disclose.

\section{References}

[1] Pfeiffer D, Berger J, Schoop C, Tauber R. A Doppler-based study on the prevalence of varicocele in German children and adolescents. Andrologia 2006;38:13-9.

[2] Kumanov P, Robeva RN, Tomova A. Adolescent varicocele: who is at risk? Pediatrics 2008;121:e53-7.

[3] Paduch DA, Skoog SJ. Current management of adolescent varicocele. Rev Urol 2001;3:120-33.

[4] The influence of varicocele on parameters of fertility in a large group of men presenting to infertility clinics. World Health Organization. Fertil Steril 1992;57:1289-93. 
[5] Sakamoto H, Ogawa Y, Yoshida H. Relationship between testicular volume and varicocele in patients with infertility. Urology 2008;71:104-9.

[6] Zini A, Boman JM. Varicocele: red flag or red herring? Semin Reprod Med 2009;27:171-8.

[7] Skoog SJ, Roberts KP, Goldstein M, Pryor JL. The adolescent varicocele: what's new with an old problem in young patients? Pediatrics 1997; 100:112-21.

[8] Al-Ali BM, Marszalek M, Shamloul R, Pummer K, Trummer H. Clinical parameters and semen analysis in 716 Austrian patients with varicocele. Urology 2010;75:1069-73.

[9] Steckel J, Dicker AP, Goldstein M. Relationship between varicocele size and response to varicocelectomy. J Urol 1993;149:769-71.

[10] Krishna Reddy SV, Basha Shaik A, Sailaja S, Venkataramanaiah M. Outcome of Varicocelectomy with different degrees of clinical varicocele in infertile male. Adv Androl 2015;2015:1-9.

[11] Shiraishi K, Takihara H, Matsuyama H. Elevated scrotal temperature, but not varicocele grade, reflects testicular oxidative stressmediated apoptosis. World J Urol 2010;28:359-64.

[12] Diamond DA, Zurakowski D, Bauer SB, et al. Relationship of varicocele grade and testicular hypotrophy to semen parameters in adolescents. J Urol 2007;178:1584-8.

[13] Seifer I, Amat S, Delgado-Viscogliosi P, Boucher D, Bignon YJ. Screening for microdeletions on the long arm of chromosome $\mathrm{Y}$ in 53 infertile men. Int J Androl 1999;22:148-54.

[14] Kass EJ, Belman AB. Reversal of testicular growth failure by varicocele ligation. J Urol 1987;137:475-6.

[15] Kurtz MP, Rosoklija I, Kringle G, Zurakowski D, Yu RN, Diamond DA. Prepubertal presentation of varicocele does not affect outcomes. J Pediatr Urol 2015, 10-3.

[16] Khasnavis S, Kogan Ba. Natural history of testicular size in boys with varicoceles. J Pediatr Urol 2015;11:, 148.e1-148.e5.

[17] Fine RG, Gitlin J, Reda EF, Palmer LS. Barriers to use of semen analysis in the adolescent with a varicocele: survey of patient, parental, and practitioner attitudes. J Pediatr Urol 2016;12: 41.e1-e41.e6.

[18] Zachmann M, Prader A, Kind HP, Häfliger H, Budliger H. Testicular volume during adolescence. Cross-sectional and longitudinal studies. Helv Paediatr Acta 1974;29:61-72.

[19] Sigman M, Jarow JP. Ipsilateral testicular hypotrophy is associated with decreased sperm counts in infertile men with varicoceles. J Urol 1997;158:605-7.

[20] Haans LC, Laven JS, Mali WP, te Velde ER, Wensing CJ. Testis volumes, semen quality, and hormonal patterns in adolescents with and without a varicocele. Fertil Steril 1991;56:731-6.

[21] Laven JS, Haans LC, Mali WP, te Velde ER, Wensing CJ, Eimers JM. Effects of varicocele treatment in adolescents: a randomized study. Fertil Steril 1992;58:756-62.

[22] Guarino N, Tadini B, Bianchi M. The adolescent varicocele: the crucial role of hormonal tests in selecting patients with testicular dysfunction. J Pediatr Surg 2003;38:120-3.

[23] Kurtz MP, Zurakowski D, Rosoklija I, et al. Semen parameters in adolescents with varicocele: association with testis volume differential and total testis volume. J Urol 2015;193:1843-7.

[24] Dubin L, Amelar RD. Varicocelectomy: 986 cases in a twelve-year study. Urology 1977;10:446-9.

[25] Hargreave TB, Liakatas J. Physical examination for varicocele. Br J Urol 1991;67:328.

[26] Costabile RA, Skoog S, Radowich M. Testicular volume assessment in the adolescent with a varicocele. J Urol 1992;147:1348-50.

[27] Walker AR, Kogan BA. Cost-benefit analysis of scrotal ultrasound in treatment of adolescents with varicocele. J Urol 2010;183:2008-11.
[28] Pryor JL, Howards SS. Varicocele. Urol Clin North Am 1987;14: 499-513.

[29] Schlesinger MH, Wilets IF, Nagler HM. Treatment outcome after varicocelectomy. A critical analysis. Urol Clin North Am 1994;21:517-29.

[30] Nieschlag E, Hertle L, Fischedick A, Abshagen K, Behre HM. Update on treatment of varicocele: counselling as effective as occlusion of the vena spermatica. Hum Reprod 1998;13:2147-50.

[31] Kroese ACJ, de Lange NM, Collins J, Evers JLH. Surgery or embolization for varicoceles in subfertile men. Cochrane Database Syst Rev 2012;10:CD000479.

[32] Jungwirth A, Giwercman A, Tournaye H, et al. European Association of Urology Guidelines on Male Infertility: The 2012 update. Eur Urol 2012;62:324-32.

[33] Cayan S, Woodhouse CRJ. The treatment of adolescents presenting with a varicocele. BJU Int 2007;100:744-7.

[34] Kocvara R, Dolezal J, Hampl R, et al. Division of lymphatic vessels at varicocelectomy leads to testicular oedema and decline in testicular function according to the LH-RH analogue stimulation test. Eur Urol 2003;43:430-5.

[35] Li F, Chiba K, Yamaguchi K, et al. Effect of varicocelectomy on testicular volume in children and adolescents: a meta-analysis. Urology 2012;79:1340-5.

[36] Paduch DA, Niedzielski J. Repair versus observation in adolescent varicocele: a prospective study. J Urol 1997;158:1128-32.

[37] Goldstein M, Gilbert BR, Dicker AP, Dwosh J, Gnecco C. Microsurgical inguinal varicocelectomy with delivery of the testis: an artery and lymphatic sparing technique. J Urol 1992;148:1808-11.

[38] Hopps CV, Lemer ML, Schlegel PN, Goldstein M. Intraoperative varicocele anatomy: a microscopic study of the inguinal versus subinguinal approach. J Urol 2003;170:2366-70.

[39] Marmar J, Benoff S. Editorial: new scientific information related to varicoceles. J Urol 2003;170:2371-3.

[40] Kocvara R, Dvoracek J, Sedlacek J, Dite Z, Novak K. Lymphatic sparing laparoscopic varicocelectomy: a microsurgical repair. J Urol 2005;173:1751-4.

[41] Riccabona M, Oswald J, Koen M, Lusuardi L, Radmayr C, Bartsch G. Optimizing the operative treatment of boys with varicocele: sequential comparison of 4 techniques. J Urol 2003;169:666-8.

[42] Mirilas P, Mentessidou A. Microsurgical subinguinal varicocelectomy in children, adolescents, and adults: surgical anatomy and anatomically justified technique. J Androl 2012;33:338-49.

[43] Fayad F, Sellier N, Chabaud M, et al. Percutaneous retrograde endovascular occlusion for pediatric varicocele. J Pediatr Surg 2011;46:525-9.

[44] Thon WF, Gall H, Danz B, Bähren W, Sigmund G. Percutaneous sclerotherapy of idiopathic varicocele in childhood: a preliminary report. J Urol 1989;141:913-5.

[45] Tauber R, Johnsen N. Antegrade scrotal sclerotherapy for treatment of testicular varicocele. Technique and late results. Urologe A 1993;32:320-6.

[46] Bogaert G, Orye C, De Win G. Pubertal screening and treatment for varicocele do not improve chance of paternity as adult. J Urol 2013;189:2298-303.

[47] Steeno O, Knops J, Declerck L, Adimoelja A, van de Voorde H. Prevention of fertility disorders by detection and treatment of varicocele at school and college age. Andrologia 1976;8:47-53.

[48] Ficarra V, Zanon G, D’Amico A, Mofferdin A, Tallarigo C, Malossini G. Percutaneous, laparoscopic, and surgical treatment of idiopathic varicocele: analysis of costs. Arch Ital Urol Androl 1998;70:57-64.

[49] Chen S-S, Chen L-K. Risk factors for progressive deterioration of semen quality in patients with varicocele. Urology 2012;79:128-32. 